\title{
Asymmetric Friedel-Crafts Reaction Using a Chiral-at-Metal Iridium Catalyst
}
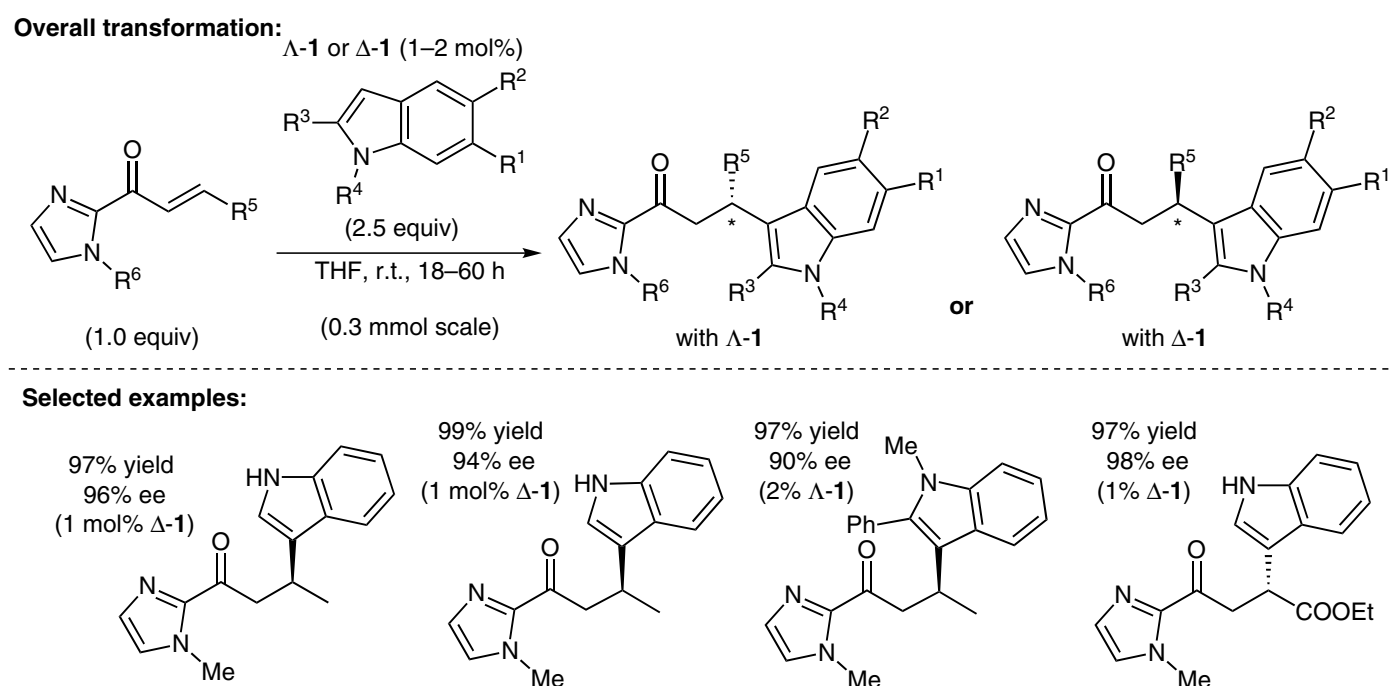

Synthesis of chiral-at-metal iridium complexes $(\Lambda-1$ and $\Delta-1)$
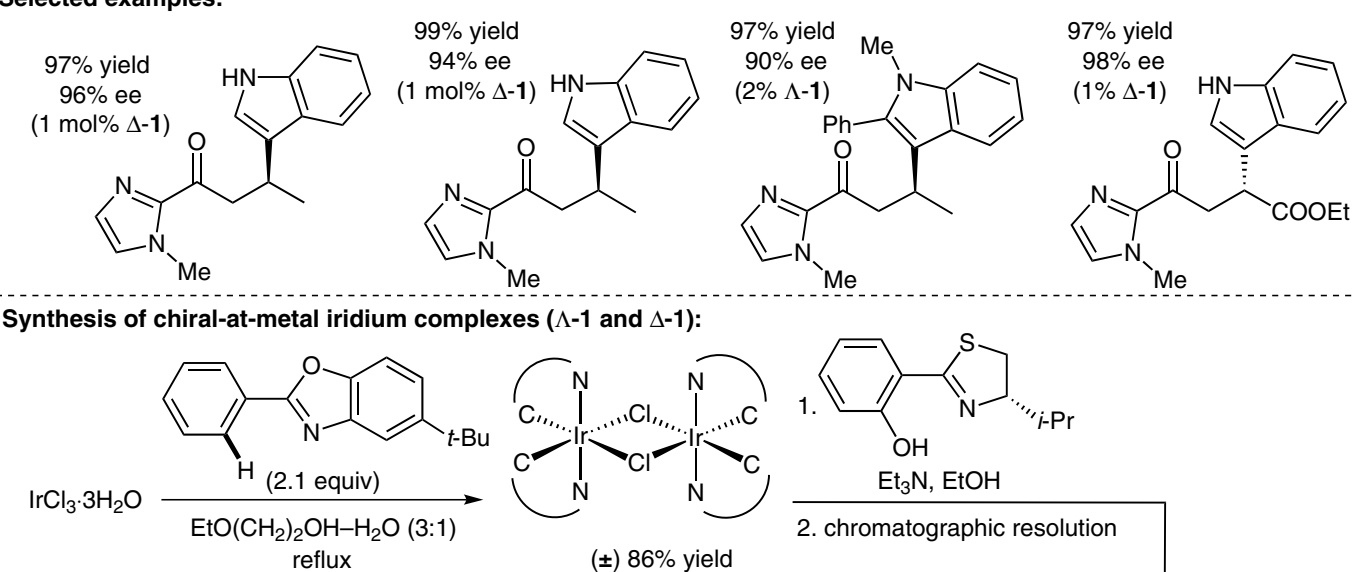

$\mathrm{Me}$

Gategory

Metal-Catalyzed

Asymmetric

Synthesis and

Stereoselective

Reactions

\section{Key words}

chiral-at-metal

iridium complexes

imidazoles

indoles

SYNFACTEn

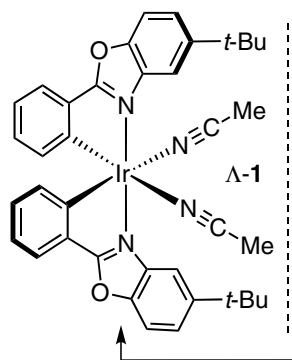

(士) $86 \%$ yield
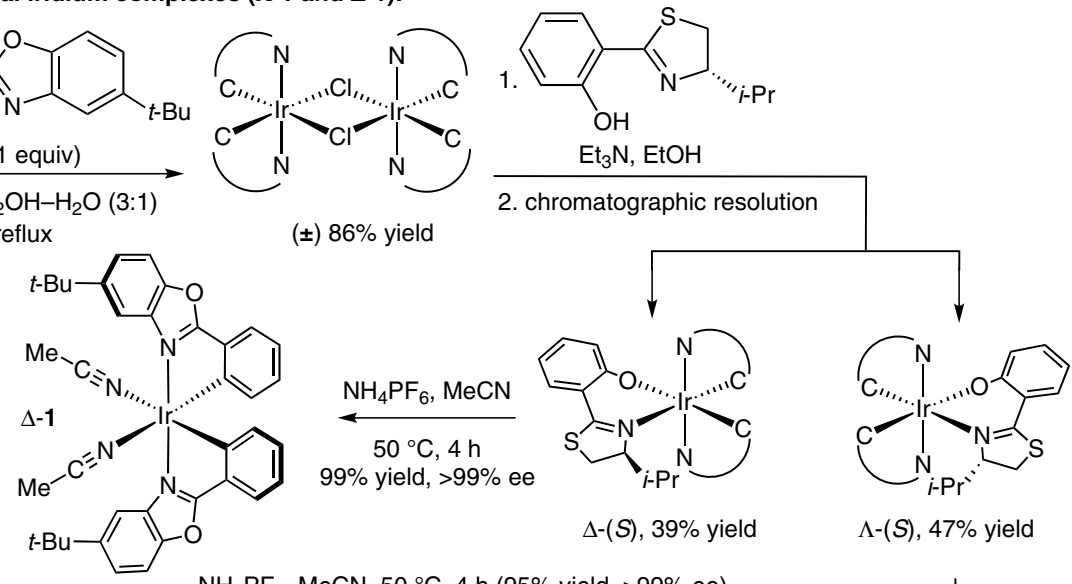

$\Delta-(S), 39 \%$ yield

$\Lambda$-(S), $47 \%$ yield

$\mathrm{NH}_{4} \mathrm{PF}_{6}, \mathrm{MeCN}, 50{ }^{\circ} \mathrm{C}, 4 \mathrm{~h}$ (95\% yield, >99\% ee)

Significance: The widespread use of asymmetric catalysis in academia and industry can be directly attributed to the vast array of synthetically and commercially available chiral ligands. However, the utilization of chiral-at-metal complexes in asymmetric catalysis is relatively underdeveloped. Here, the authors report the efficient synthesis of a chiral-at-iridium catalyst and its application to an asymmetric Friedel-Crafts reaction.

SYNFACTS Contributors: Mark Lautens, David A. Petrone Synfacts 2014, 10(5), 0487 Published online: 17.04.2014 DOI: 10.1055/s-0033-1341177; Reg-No.: L03514SF
Comment: The authors present the asymmetric Friedel-Crafts reaction of indoles and acyl imidazole derivatives using a chiral-at-iridium complex as catalyst. The reaction proceeds with excellent yields and selectivities by employing a low loading (1-2 mol\%) of this interesting catalyst. The authors suggest that once coordinated, the achiral ligands block the re face of the indole, resulting in a highly selective si-face attack. 